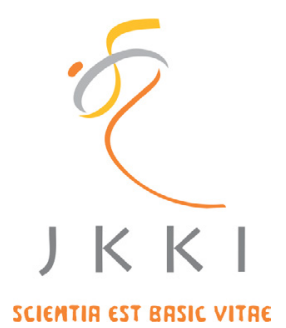

Jurnal Kedokteran dan Kesehatan Indonesia

Indonesian Journal of Medicine and Health

Journal homepage : https://journal.uii.ac.id/JKKI

\title{
Delayed lactogenesis II and unsuccessful exclusive breastfeeding
}

Miranti Dewi Pramaningtyas*1

${ }^{1}$ Department of Physiology, Faculty of Medicine, Universitas Islam Indonesia, Yogyakarta, Indonesia

\begin{tabular}{l}
\hline ARTICLE INFO \\
*Corresponding author: \\
mirantidewip@gmail.com \\
\hline DOI:10.20885/JKKI.Vol10.Iss2.art2 \\
Copyright @2019 Authors. \\
This is an open access article \\
distributed under the terms \\
of the Creative Commons At- \\
tribution-NonCommercial 4.0 \\
International Licence (http:// \\
creativecommons.org/licences/ \\
by-nc/4.0/).
\end{tabular}

\section{EDITORIAL}

B reast milk is the main source of nutrition for newborns. Nutrients and bioactive substances that are important for babies are found in breast milk. Cells, anti-infectious and anti-inflammatory agents, growth factors, and prebiotics are bioactive factors in breast milk. ${ }^{1}$ These contents are essential to ensure the growth, health, and cognitive development of human infants. ${ }^{2}$ World Health Organization recommends mothers to exclusively breastfeed infants for the first six months. Adequate nutritional complementary foods begin at the age of 6 months along with continued breastfeeding until the age of 2 years or more. ${ }^{3}$

Exclusive breastfeeding has many benefits for both mother and baby. Benefits for babies include reducing the incidence of respiratory tract infections, otitis media, gastrointestinal infections, allergies, obesity, diabetes, and sudden infant death. Breastfeeding also helps the development of nerves and the intelligence of infants. ${ }^{4,5}$ Benefits of breastfeeding for mothers include reducing the incidence of postpartum haemorrhage, accelerating uterine involution, risk of hypertension, type 2 diabetes, metabolic syndrome, and hyperlipidemia., ${ }^{4,6}$ Although exclusive breastfeeding is known to provide many benefits for mothers and infants, coverage worldwide only reaches $40 \%{ }^{3}$ Coverage of exclusive breastfeeding in America is even only $18.8 \%{ }^{7}$ In Indonesia coverage of exclusive breastfeeding reaches $49.8 \% .{ }^{8}$ Some of the factors that contributed to the achievement of exclusive breastfeeding include the knowledge of maternal factors, maternal body mass index, and delayed lactogenesis II.,10

Lactogenesis is the activity of the number of mammary cells to producemilk. It takes a two-stage event, the initiation and activation of the secretory. The first stage of lactogenesis (lactogenesis I) occurs in during the second half of pregnancy. The placenta provides elevated progesterone concentrations that prevent further differentiation. The second stage of lactogenesis (lactogenesis II) begins after shipment with abundant milk manufacturing. The rapid drop in progesterone, as well as the presence of elevated levels of prolactin, cortisol, and insulin, stimulates this stage with the removal of the placenta at delivery. ${ }^{11}$

Delayed lactogenesis II is a condition that starts from the failure of activation of the lactogenesis II process. In this condition, breast milk does not come out until 72 hours after postpartum. ${ }^{12}$ This condition raises the perception of lack of milk production. In the initial condition after giving birth, nursing mothers who experience this condition have the possibility of having difficulty being able to breastfeed exclusively for up to 6 months. ${ }^{13,14}$ Some mothers even stop breastfeeding in the first two weeks. ${ }^{7}$ If breast milk does not come out within the first 72 hours, it must immediately look for the causes and how to overcome them. ${ }^{12}$ This shows the critical point in the early hours of breastfeeding to be an important period for the success of exclusive breastfeeding. In some studies, difficulty in breastfeeding is often cited as an excuse to stop breastfeeding earlier than expected. ${ }^{14}$ 
Delayed lactogenesis II can occur in several conditions. Mothers with diabetic, prolonged labour, and retained placenta may experience delayed lactogenesis II. Slower decline in progesterone levels can also be a factor in the delay in breast milk production. ${ }^{12}$ Progesterone which falls slowly is generally experienced by obese mothers. Overweight before pregnancy and obesity reduces prolactin response for breastfeeding in the first week postpartum. ${ }^{15}$

There is an excessive and abnormal fat accumulation in obesity. ${ }^{16}$ In woman, the deposition of fat is influenced by the hormones estrogen and progesterone. ${ }^{17}$ The concentration of progesterone in an obese woman is higher in the early postpartum period than woman inthe normal weight rangeBecause adipose tissue is an extra placental source of the hormone. ${ }^{15}$ Progesterone can inhibit basal prolactin promoter activity ${ }^{18}$ Although in some sources it is also mentioned that prolactin is not very responsible for lactogenesis II, other sources say that prolactin is a hormone that plays a role in breast milk synthesis in the early days of postpartum. ${ }^{19}$ The mechanism of inhibition is partly mediated by a cross between the progesterone receptor and prolactin signalling to inhibit the induction of milk protein gene expression. Another mechanism is by inhibiting the closure of tight junctions. ${ }^{20}$ When prolactin is obstructed in an obese condition, delayed lactogenesis II can occur.

The timely onset of lactogenesis II is a very important factor for the success of exclusive breastfeeding. World Health Organization and Unicef recommend breastfeeding as early as possible after postpartum. ${ }^{21}$ This is expected to reduce the risk of late-onset of lactogenesis II. Further studies to reduce the risk of delayed lactogenesis II still need to be done. These efforts are expected to increase exclusive breastfeeding coverage and improve the quality of maternal and infant health.

\section{REFERENCES}

1. Ballard O, Morrow AL. Human milk composition: nutrients and bioactive factors. Pediatric Clinics of North America. 2013;60(1):49-74.

2. Isaacs EB, Fischl BR, Quinn BT, Chong WK, Gadian DG. Impact of breast milk on IQ brain size and white matter development. Pediatric Research. 2010;67(4):357-62.

3. World Health Organization. Infant and young child feeding: model Chapter for textbooks for medical students and allied health professionals. WHO; 2009.

4. American Academy of Pediatrics. Breastfeeding and the use of human milk. Pediatrics. 2012;129(3):e827-41.

5. Shamir R. The Benefits of Breast Feeding. Nestlé Nutrition Institute workshop series. 2016;86:67-76.

6. Demirci J, Schmella M, Glasser M, Bodnar L, Himes KP. Delayed lactogenesis II and potential utility of antenatal milk expression in women developing late-onset preeclampsia : a case series. BMC Pregnancy and Childbirth. 2018;18(68).

7. Fu M, Zhang L, Ahmed A, Plaut K, Haas DM, Szucs K, et al. Does circadian disruption play a role in the metabolic - hormonal link to delayed lactogenesis II ? Frontiers in nutrition. 2015;2:4.

8. Yohmi E, Marzuki NS, Nainggolan E, Partiwi IGAN, Syarif BH, Oswari H. Prevalence of exclusive breastfeeding in Indonesia: a qualitative and quantitative study. Paediatrica Indonesiana. 2015;55(6):302-8.

9. Zielińska MA, Sobczak A, Hamułka J. Breastfeeding knowledge and exclusive breastfeeding of infants in first six months of life. Roczniki Państwowego Zakładu Higieny. 2017;68(1):51-9.

10. Skouteris H, Nagle C, Fowler M, Kent B, Sahota P, Morris H. Breastfeeding in high-income countries : a systematic review. Breastfeeding Medicine. 2014;9(3):113-27.

11. Pillay J, Davis TJ. Physiology, Lactation. Treasure Island (FL): StatPearls Publishing; 2019.

12. Lawrence RA, Lawrence RM. Breastfeeding: A guide for the medical profession. 8th ed. Philadeplhia: Elsevier; 2016.

13. Brownell E, Howard CR, Lawrence RA, Dozier AM. Does delayed onset lactogenesis II predict the cessation of any or exclusive breastfeeding? The Journal of Pediatrics. 2012;161(4):60814.

14. Wagner EA, Chantry CJ, Dewey KG, Nommsen-Rivers LA. Breastfeeding Concerns at 3 and 7 Days Postpartum and Feeding Status at 2 Months. Pediatrics. 2013;132(4):865-75.

15. Rasmussen KM, Kjolhede CL. Prepregnant overweight and obesity Diminish the Prolactin Re- 
sponse to Suckling in the First Week Postpartum. Pediatrics. 2004;113(5):e465-71.

16. Yang $Q$, Xiao T, Guo J, Su Z. Complex relationship between obesity and the fat mass and obesity Locus. International Journal of Biological Sciences. 2017;13(5):615-29.

17. Toth MJ, Poehlman ET, Matthews DE, Coss MJMAC, Michael J, Poehlman ET, et al. Effects of estradiol and progesterone on body composition, protein synthesis , and lipoprotein lipase in rats. American Journal of Physiology-Endocrinology and Metabolism. 2001;280:E496-501.

18. Mijiddorj T, Kanasaki H, Purwana I, Unurjargal S, Oride A. Effects of estradiol and progesterone on prolactin transcriptional activity in somatolactotrophic cells. Endocrine Journal. 2012;59(10):867-79.

19. Powe CE, Puopolo KM, Newburg DS, Lönnerdal B, Chen C, Allen M, et al. Effects of Recombinant Human Prolactin on Breast Milk Composition. Pediatrics. 2011;127(2):e359-66.

20. Obr A, Edwards DP. The biology of progesterone receptor in the normal mammary gland and in breast cancer. Molecular and Cellular Endocrinology. 2012;357(1-2):4-17.

21. World Health Organization. 10 facts on breastfeeding. WHO. 2017. 